\title{
THE EFFECT OF DIFFERENT IMPLANT ABUTMENT MATERIALS ON THE STRESS DISTRIBUTION TO THE BONE IMPLANT CONTACT
}

\author{
Abeer Atef Younes* , Amany Mohamed Morsel ${ }^{* *}$, Mohamed Seddik Kamel $^{* *}$, \\ Heba Mohamed El Tokhey ${ }^{* * *}$ and Khaled Mohamed Ali****
}

\begin{abstract}
Purpose: evaluating the effect of different implant-abutment materials on the stress distribution to the bone-implant contact using histomorphometric analysis.

Materials and methods: In the experimental animal work fifteen adult male dogs were selected; the third premolar on the right side of the mandible was extracted. Titanium implant fixture inserted in the socket then left for three months for healing. Grouping: 5Titanium, 5 zirconia and 5 BIOHPP abutments were screwed on the implant fixtures (five dogs for each one). Impression was taken to fabricate crowns allowing the dogs to masticate on it for the other three months, and then all dogs were euthanized. Block sections from the mandible were taken, prepared for histomorphometric analysis (scanning electron microscope), and then BIC\% was measured.
\end{abstract}

Results: SEM: showed that BIC\% was higher in BIOHPP abutment followed by Zirconium abutment and titanium abutment with a significant statistical difference between the three groups $(\mathrm{F}=4.222, \mathrm{P}=0.025)$

Conclusion: Using more flexible abutment material (BIOHPP) transmitted fewer stresses on the surrounding bone with better bone-implant contact than the rigid materials.

Keywords: bone-implant contact (BIC \%), BIOHPP, histomorphometric,finite element analysis, stress distribution.

\section{INTRODUCTION}

Osteointegration is a biological fixation through continuous bone apposition and remodeling toward the implant. It is critical for implant stability, and is considered a prerequisite for implant loading and long term clinical success of endo osseous dental implant $^{1}$.

Despite of this success, clinical problems may occur with implants because their biomechanical behavior is considerably different from that

\footnotetext{
* Assistant Lecturer, Fixed Prosthodontics Department, Faculty of Dentistry, Tanta University

** Assistant Professor, Fixed Prosthodontics Department, Faculty of Dentistry Tanta University

*** Professor of Oral Biology Department Faculty of Dentistry Tanta University

**** Lecturer of Surgery and Anathesiology Faculty of Veterinary Medicine Cairo University
} 
of natural teeth. The implant/bone interface demonstrates much less resilience compared with that of the tooth/bone interface ${ }^{2}$.

Therefore, the stress created during implantsupported prosthesis insertion and masticatory function can be more directly transmitted to the bone $^{3}$. The absence of implant resilience necessitates higher precision in the planning, treatment, and accurate selection of the prosthetic material during fabrication of implant dental appliances ${ }^{4}$. several techniques to lower the stress on the crestal bone, such as increasing the implant surface or decreasing the biomechanical forces that may be decreased in magnitude, duration, type, direction, and application. 5, 6

Another possible method to reduce the stress at the crestal bone level is to use an abutment made of a flexible material that deforms within its elastic limit absorbing a part of applied loed. ${ }^{7}$

Ceramic reinforced PEEK (BIOHPP) materials have been developed to improve the mechanical properties of the restoration in comparison to titanium and zirconia materials because the elastic modulus very closes to human bone.

It is essential to understand and improve the load distribution from the prosthesis to the implants and bone by trying to use this new material and evaluating its effect on stress distribution on the bone. Therefore, using the BIOHPP as permanent abutment and comparing its effect on the bone implant contact (BIC \%) in comparison to titanium and zirconia abutments in experimental animal study.

\section{MATERIAL AND METHODS}

Fifteen adult male dogs were used the selected dogs should be healthy with an average weight around (15-20 kg) and an average age of
(2-3 years).$^{8}$ then medicated properly using systematic course of antibiotic (cefitriaxone) at a dose of $25 \mathrm{mg} / \mathrm{kg}$ B.W.I.M. Tooth extraction was performed under general anesthesia then a preoperative $\mathrm{x}$-ray was taken before the extraction of the third premolar tooth to examine the roots.

A root form titanium implant fixture (12m length, $4 \mathrm{~mm}$ diameter) was inserted in narrower extraction socket immediately after extraction and slightly lingual to avoid destruction of the buccal bone at a torque of $30 \mathrm{Ncm}$ till the implant shoulder become $1 \mathrm{~mm}$ below the bone crest. The drilling sequence was done following the manufacturer instructions for the implant used then left for three months till osteointegration occur.

\section{According to the research grouping:}

\begin{tabular}{|l|l|l|}
\hline $\begin{array}{l}\text { - Group 1 } \\
\text { (Control): }\end{array}$ & $\begin{array}{l}\text { (5) Titanium } \\
\text { abutments }\end{array}$ & $\begin{array}{l}\text { Right mandibular side } \\
\text { of five dogs }\end{array}$ \\
\hline - Group 2: & $\begin{array}{l}\text { (5) Zirconia } \\
\text { abutments }\end{array}$ & $\begin{array}{l}\text { Right mandibular side } \\
\text { of five dogs }\end{array}$ \\
\hline - Group 3: & $\begin{array}{l}\text { (5) BIOHPP } \\
\text { abutments }\end{array}$ & $\begin{array}{l}\text { Right mandibular side } \\
\text { of five dogs }\end{array}$ \\
\hline
\end{tabular}

The Ti abutments were screwed on the implant fixtures of using five dogs (control group I) while the zirconia and BIOHPP abutments were screwed in the other ten dogs (five dogs for each one) (experimental group 2 and 3 ).

All prefabricated abutments were straight with 6 degree of taper (9.5 mm length, 3.8 platform, and screw 2.2)* adjusting the abutments to avoid contact with opposing teeth then confirmatory preapical $\mathrm{x}$-ray was taken after implant abutment complex inserted.

Impression was taken using silicon based impression material ${ }^{* *}$ in special tray to fabricate porcelain fused to metal crowns cemented on the abutments allowing the dogs to masticate on it for other three months to subject the implant to masticatory forces for six months after implant insertion.

\footnotetext{
* Sky elegance abutment, Bredent, Senden, Germany.

** Zhermack Zetaplus condensation silicon, Badia polesine,Italy.
} 


\section{Specimen harvest:}

Just before the time of scarifying a preapical $\mathrm{x}$-ray films were taken for each implant to detect the changes in the bone level, and bone deposition around the implant. Dogs were euthanatized by intravenous overdose infusion of thiopental sodium under systemic ketamine and xylazine. Mandibles were harvested and divided into blocks for each implant. Block sections, each section containing one implant were prepared for cutting.

Using ISOMET 4000* each block cut in a buccolingual plane using a blade fitted in a precision slicing machine which allowed cutting precisely the blocks, including bone tissue and titanium implants. The device cut specimens $10 \mathrm{~mm}$ thick. Specimens were polished to a finer thickness using 800to 2400 grit silicon carbide paper.

Samples were histologically evaluated with scanning electron microscope (SEM) using different magnification100x, 200x, 1000x, 2000x. A control histological specimen was block sectioned from normal tissues in the premolar area.

BIC \% of the three consecutive best threads which considered a well-documented method of measuring osseointegration. It was quantified histomorphometrically using NIH Image analysis software.

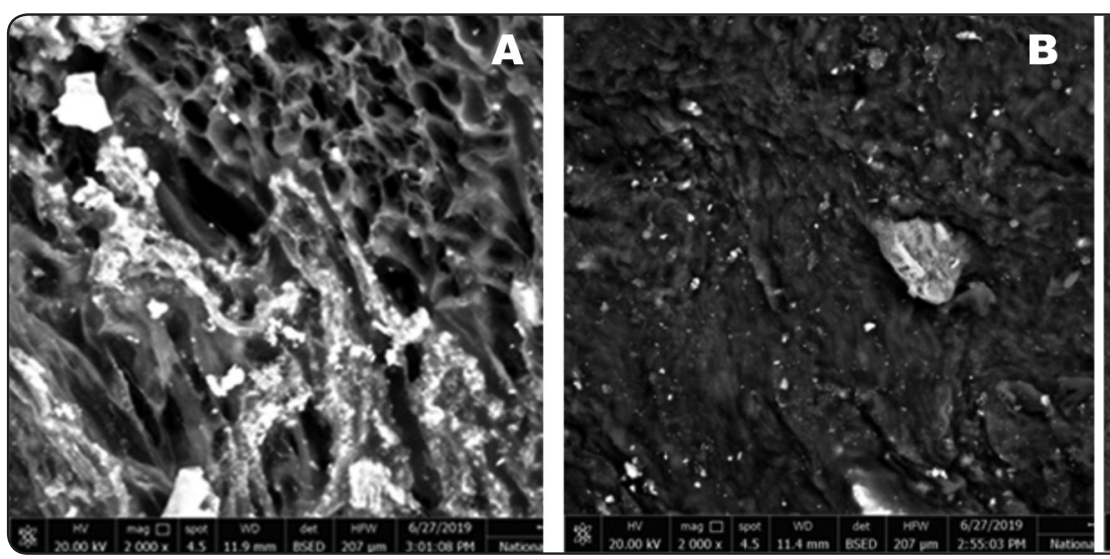

Fig. (1) General view of the titanium implant and the surrounding

bone with a selected part for magnification.

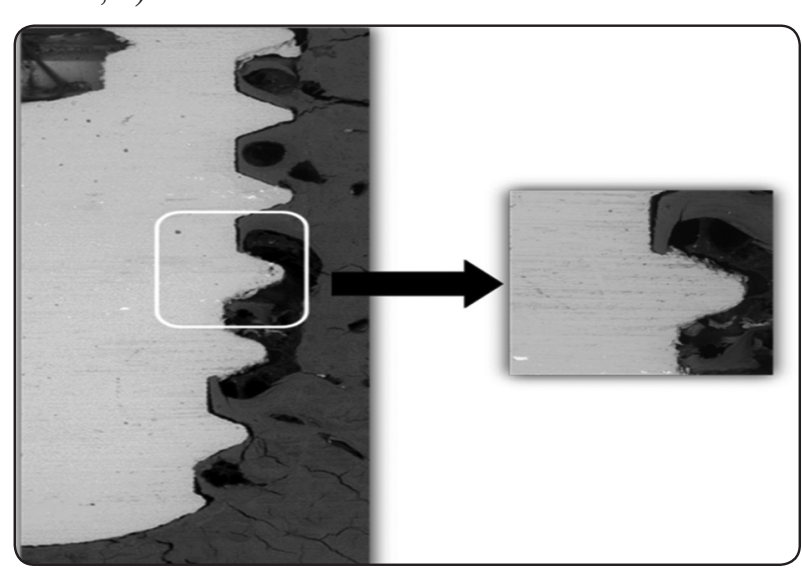
those in zirconia group as it show mixed parts of mineralized collagen fibers and mature bone with clear haversian system. It also showed nearly no gab at the bone implant junction (fig $1,2)$

Using scanning electron microscope to captured images of the bone implant contact showed that:

- The control (Titanium group) showed more mineralized collagen fibers aligned parallel to the implant surface and very narrow gab appeared at the bone implant junction.

- Zirconia group showed more condensed, compact, mature bone in comparison to titanium group at the dental implant junction with newly formed osteocyte cells

- BIOHPP group with more newly formed mature compact bone than titanium group but less than

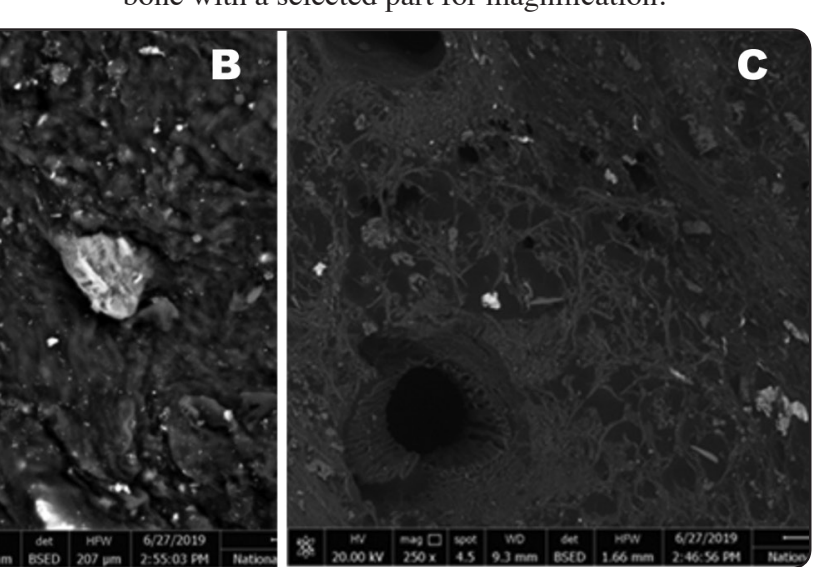

Fig. (2) Scanning electron microscope (SEM) of the (A) Titanium, (B) Zirconia, (c) BIOHPP abutments specimens at higher magnification magnification $2000 x$

\footnotetext{
* Buehler, an ITW Company, 41 Waukegan Road Lake Bluff, Illinois60044 USA.
} 


\section{Bone implant contact (BIC \%):}

The bone implant contact percentage was higher in BIOHPP abutment (group 3) (73.54 \pm 7.78$)$ $\%$ followed by Zirconium abutment (group 2) $(66.02 \pm 7.93) \%$ and titanium abutment (group 1) $(64.52 \pm 6.59) \%$ (table 1)

On comparing the three implant abutments' materials as regard BIC \% a significant statistical difference between the three groups $(\mathrm{F}=4.222, \mathrm{P}=$ 0.025 ) (Table 1).

A significant statistical difference on comparing BIOHPP abutment (group 3) to Titanium abutment (group 1) and to Zirconium abutment (group 2) as regard $\mathrm{BIC} \% ;(\mathrm{t}=2.813, \mathrm{P}=0.012)$ and $(\mathrm{t}=$ $2.149, \mathrm{P}=0.046)$ respectively. While no significant difference was found on comparing BIC $\%$ in group 2 to group 1

TABLE (1) Comparison between the three implant abutments' materials as regard bone implant contact (BIC\%) using one-way ANOVA:

\begin{tabular}{|c|c|c|c|c|c|}
\hline & Titanium & Zirconium & BIOHPP & F & P \\
\hline $\begin{array}{r}\text { BIC } \\
(\boldsymbol{\%})\end{array}$ & $64.52 \pm 6.59$ & $66.02 \pm 7.93$ & $73.54 \pm 7.78$ & 4.222 & $0.025 *$ \\
\hline
\end{tabular}

* Significant Statistical Difference

\section{DISCUSSION}

Bone cells respond to a mechanical stress induced local bone deformation. In steady state the bone adapts itself to the stresses applied. The bone becomes overloaded and compensated by forming new bone with slightly increased stresses. If the stress goes beyond a threshold that exceeds the bone's capacity therefore fatigue fracture will occur. $^{8}$ the impact of the load on the bone or the resultant strain in the bone is the actual cause of bone changes or injury. ${ }^{9}$
For medical advancement of human health, the use of experimental animal research has contributed massively as the mechanical properties of most bone mammals' tissues are not substantially different from human. The Selecting of beagle dogs concluded that Dog and human dentitions were diphyodontics with two sets of teeth (deciduous and permanent). ${ }^{10}$

Bite forces for normal women/men ranging from $(383 \mathrm{~N} / 547 \mathrm{~N})$ or $(442 \mathrm{~N} / 512 \mathrm{~N})$, While the bite force was observed in dogs of varying size with a mean around $256 \mathrm{~N}$ which very similar to those of humans. ${ }^{11,1213}$

Histomorphometric analysis is the most commonly used method for examining the implantsoft and hard tissue interface. The histological preparation techniques can be classified into two main categories: tissue processing with the implant in situ and tissue processing with the implant removed. The selected method of our research was tissue processing with the implant in situ because maintaining the implant in the section allowed the tissue interface to be examined directly in relation to the implant. ${ }^{14}$

In current study scanning electron microscope (SEM) was the selected method for examining the specimens with implant in situ that prevents implant cutting. It provides three dimensional architecture of the implant-tissue interface and useful for assessing density differences for surface areas of calcified tissues, resulting in images with different gray levels. ${ }^{15}$

The risk of bias has been avoided as there is no need for staining and the image analysis process is standardized. BIC measurements were more accurate than the traditional optical microscopy as because SEM images have a much higher resolution and a much higher contrast between implant and bone..$^{15}$

Therefore we used scanning electron microscope (SEM) to analyze the implant new bone tissue interface and determine the $\mathrm{BIC} \%$ of the prepared samples of each group, the BIOHPP abutment 
showed higher BIC\% (73\%) which followed by zirconia $(66 \%)$ and titanium $(64.4 \%)$ with a statistical difference between zirconia and BIOHPP, whereas there was no statistical difference between zirconia and titanium.

This was supported by the scanning electron microscope images showing more intact bone implant contact with very narrow gab in some areas and no gab in the most of the surfaces in BIOHPP groups, this reinforced the fact that peek material is a more flexible material with low modulus of elasticity which transmits less forces to the bone and enhanced more bone implant contact(BIC). ${ }^{16}$

The aim of Igarashi et al. ${ }^{17}$ was to examine the changes and improvements of the hard and soft tissue around dental implant using three different materials in dog models with micro grooved collar in a dog model. They found that the BIC to be largest in Ce-TZP/Al2O3-g (the most flexible material) followed by Ti-g and Y-TZP-g. All groups showed average mean of BIC\% was more than $60 \%$ which in agree with our research work.

While Mehl et al. ${ }^{18}$ studied the effect on the cervical implant bone and soft tissue of four different abutment materials and the adhesive joint of twopiece abutments. No significant influence detected between any of the mentioned abutment materials with regard to bone loss or soft tissue anatomy these results disagree with our study results.

\section{CONCLUSION}

1- Using more flexible abutment material like BIOHPP transmitted less stresses on the surrounding bone with better bone implant contact than the rigidly used materials.

2- BIOHPP abutment showed a significant BIC\% in comparison to titanium and zirconia abutments.

3- Using BIOHPP as a permanent abutment approved its ability to withstand the masticatory forces without failure with a closer behavior to conventional titanium abutment.

\section{REFERENCES}

1. Parithimarkalaignan S, Padmanabhan T V. Osseointegration: An Update -a review. J Indian Prosthodont Soc 2013; 13:2-6.

2. Tanino F, Hayakawa I, Hirano S, Minakuchi S. Finite element analysis of stress-breaking attachments on maxillary implantretained overdentures. Int J Prosthodont 2007; 20:193-8.

3. Skalak R. Biomechanical considerations in osseo-integrated prostheses. J Prosthet Dent 1983; 49:843-68.

4. Bacchi A, Consani RL, Mesquita MF, dos Santos MB. Stress distribution in fixed-partial prosthesis and peri-implant bone tissue with different framework materials and vertical misfit levels: a three-dimensional finite element analysis. J Oral Sci 2013; 55:239-44.

5. Zarb GA. On parafunctional considerations in implant therapy. Int J Prosthodont 2014; 27:199.

6. Cidade CP, Pimentel MJ, Amaral RC, Nbilo MA, Barbosa JR. Photoelastic analysis of all-on-four concept using different implants angulations for maxilla. Braz Oral Res 2014; 28:1-7.

7. Nakamra K, Kanno T, Milleding P, Ortengren U. Zirconia as a dental implant abutment material: A systematic review. Int J Prosthodont 2010; 23:299-309.

8. Frost HM. Perspectives: bone's mechanical usage windows. Bone Miner. 1992; 19:257-71.

9. Frost HM. A 2003 update of bone physiology and Wolff s law for clinicians. Angle Orthod. 2004; 74:3-15.

10. Tummers M, Yamashiro T, Thesleff I. Modulation of Epithelial Cell Fate of the Rootin vitro. J Dent Res. 2007; 86:1063-7.

11. Raadsheer MC, van Eijden TMGJ, van Ginkel FC, PrahlAndersen B. Human jaw muscle strength and size in relation to limb muscle strength and size. Eur J Oral Sci. 2004; 112:398-405.

12. Cosme DC, Baldisserotto SM, Canabarro S de A, Shinkai RS. Bruxism and voluntary maximal bite force in young dentate adults. Int J Prosthodont. s. f.; 18:328-32.

13. Lindner DL, Marretta SM, Pijanowski GJ, Johnson AL, Smith CW. Measurement of bite force in dogs: a pilot study. J Vet Dent. 1995;12:49-52. 
14. Chai WL, Moharamzadeh K, Brook IM, Van Noort R. A review of histomorphometric analysis techniques for assessing implant-soft tissue interface. Biotech Histochem. 2010; 86:242-54.

15. Manresa C, Bosch M, Manzanares MC, Carvalho P, Echeverría JJ. A new standardized-automatic method for bone-to-implant contact histomorphometric analysis based on backscattered scanning electron microscopy images. Clin Oral Implants Res. 2014; 25:702-6.

16. Brizuela A, Herrero-Climent M, Rios-Carrasco E, RiosSantos J, Pérez R, Manero J, et al. Influence of the Elastic
Modulus on the Osseointegration of Dental Implants. Materials (Basel). 2019; 12:980.

17. Igarashi K, Naharaka K, Kobayashi E, Watanabe F, HagaTsujimura M. Hard and soft tissue responses to implant made of three different materials with microgrooved collar in a dog model. Dent Mater J. 2018; 37:964-72.

18. Mehl C, Gaßling V, Schultz-Langerhans S, Açil Y, Bähr $\mathrm{T}$, Wiltfang J, et al. Influence of Four Different Abutment Materials and the Adhesive Joint of Two-Piece Abutments on Cervical Implant Bone and Soft Tissue. Int J Oral Maxillofac Implants. 2016; 31:1264-72. 